\title{
ORIGINAL ARTICLE \\ Food and nutrient intake and adherence to dietary recommendations during pregnancy: a Nordic mother-child population-based cohort
}

\author{
Carina Madelen Saunders',2*, Eva Maria Rehbinder2,3, Karin C. Lødrup Carlsen 1,2, \\ Malén Gudbrandsgard', Kai-Håkon Carlsen 1,2, Guttorm Haugen',4, Gunilla Hedlinn,6, \\ Christine Monceyron Jonassen ${ }^{7,8}$, Katrine Dønvold Sjøborg' ${ }^{9}$ Linn Landrø ${ }^{3}$, Björn \\ Nordlund ${ }^{5,6}, K_{\text {nut Rudi }}^{8}$, Håvard O.Skjerven ${ }^{1,2}$, Cilla Söderhäll ${ }^{5,6}$, Anne Cathrine Staff ${ }^{2,4}$, \\ Riyas Vettukattil ${ }^{1,2}$ and Monica Hauger Carlsen ${ }^{10}$ on behalf of the PreventADALL \\ study group
}

\begin{abstract}
'Division of Paediatric and Adolescent Medicine, Oslo University Hospital, Oslo, Norway; ${ }^{2}$ Faculty of Medicine, Institute of Clinical Medicine, University of Oslo, Oslo, Norway; ${ }^{3}$ Department of Dermatology, Oslo University Hospital, Oslo, Norway; ${ }^{4}$ Division of Obstetrics and Gynaecology, Oslo University Hospital, Oslo, Norway; ${ }^{5}$ Astrid Lindgren Children's Hospital, Karolinska University Hospital, Stockholm, Sweden; 'Department of Women's and Children's Health, Karolinska Institutet, Stockholm, Sweden; ${ }^{7}$ Genetic Unit, Centre for Laboratory Medicine, Østfold Hospital Trust, Kalnes, Norway; ${ }^{8}$ Faculty of Chemistry, Biotechnology and Food Science, Norwegian University of Life Sciences, Ås, Norway; 'Department of Obstetrics and Gynaecology, Østfold Hospital Trust, Kalnes, Norway;

${ }^{10}$ Department of Nutrition, Institute of Basic Medical Sciences, University of Oslo, Oslo, Norway
\end{abstract}

\section{Popular scientific summary}

- This population-based study showed that pregnant women had a high intake of fiber, vegetables, and fish.

- Median intake of red meat, salt, and saturated fat was higher than recommended in most pregnancies.

- Over half of the pregnant women likely had a folate intake below the recommended intake.

- Intake of alcohol and coffee exceeded the recommended levels in almost half of the participants, and increased with an increase in the level of education.

- Intervention strategies may be considered to improve maternal nutrition in pregnancy.

Abstract

Background: A woman's food intake during pregnancy has important implications not only for herself but also for the future health and well-being of her child. Suboptimal dietary quality has been consistently reported in many high-income countries, reflecting poor adherence to dietary guidelines.

Objective: This study aimed to explore the intake of food and nutrients in a cohort of pregnant women in Norway and their adherence to Nordic Nutrition Recommendations (NNR) and Norwegian food-based guidelines (NFG).

Design: We investigated the dietary intake in 1,674 pregnant women from the mother-child birth cohort, PreventADALL, recruited at approximately 18-week gestational age. Dietary intake was assessed by an electronic validated food frequency questionnaire (PrevFFQ) in the first half of pregnancy.

Results: Total fat intake was within the recommended intake (RI) range in most women; however, the contribution of saturated fatty acids to the total energy intake was above RI in the majority (85.2\%) of women. Carbohydrate intake was below RI in $43.9 \%$ of the women, and $69.5 \%$ exceeded the RI of salt. Intakes of fiber, vegetables, and fish were high in a large part of the population. Many women had a high probability of inadequate intakes of the following key micronutrients during pregnancy: folate $(54.4 \%)$, iron (49.6\%), calcium (36.2\%), vitamin D (28.7\%), iodine (24.4\%), and selenium (41.3\%). A total of $22.8 \%$ women reported an alcohol intake of $>1 \mathrm{~g} /$ day, and $4.4 \%$ reported an alcohol intake of $>10 \mathrm{~g} /$ day. Women with 
higher educational levels showed a tendency towards healthier eating habits, except for higher intakes of alcohol and coffee, compared to women with lower educational level.

Discussion: Excessive saturated fat intake and limited intake of many important micronutrients during pregnancy were common, potentially increasing the risk for adverse pregnancy and birth outcomes.

Conclusions: This study highlights the need for improved nutritional guidance to pregnant women across all educational levels.

Keywords: nutrients; dietary intake; Nordic diet; fetal programming; food intake; nutritional recommendations

To access the supplementary material, please visit the article landing page

Received: I8 August 2019; Revised: 25 November 20 19; Accepted: 26 November 20 I9; Published: 20 December 20 I9

1 healthy, nutrient-rich, and energy-appropriate diet during pregnancy is crucial for optimal development and growth of the fetus (1). Nutrient requirement is considerably increased during pregnancy and stands in contrast to the recommended modest increase in total energy intake throughout all three trimesters $(1,2)$. Malnutrition in women and children is a major global health issue, and pregnant women are at increased risk of micro- and macronutrient deficiency (3).

The significance of dietary intake and lifestyle factors during pregnancy has been accentuated with the increasing knowledge of fetal programming on later health outcomes (4-6). Women with a Western diet, characterized by high amounts of saturated fat, sugars, processed foods, and low amounts of fiber (7), during pregnancy are at an increased risk of delivering a child with lower birth weight, whereas adherence to Mediterranean dietary patterns, with high intakes of fruits, vegetables, and fish, has been associated with a decreased risk of delivering infants with lower birth weight $(8,9)$. Moreover, maternal micro- and macronutrient intake may directly influence the offspring's organ development, function, and metabolism (10).

In high-income countries, maternal malnutrition tends to manifest itself as a combination of macronutrient overnutrition and micronutrient undernutrition (11). The unfavorable profile of macronutrient intake is commonly reflected by low intake of complex carbohydrates, and high intakes of fat, saturated fat, and salt during pregnancy. Due to the increase in lower-quality diets, inadequate intakes of folate, iron, and vitamin D during pregnancy have consistently been reported in the United States, the United Kingdom, and other European countries (12, 13). Iodine deficiency among pregnant ladies is prevalent in many parts of Europe (14). Although women are advised to abstain from alcohol consumption during pregnancy, about a quarter of women in the general European population reported alcohol use during pregnancy (15).

Nordic countries have for several decades collaborated in developing guidelines for the intake of nutrients, resulting in the Nordic Nutrition Recommendations
(NNR) (16). The NNR are intended to support health and prevent diet-associated diseases by setting dietary recommendations for the intake of energy-providing nutrients, intake of micronutrients, as well as fiber and alcohol intake. In 2011, the Norwegian Council for Nutrition published the Norwegian food-based dietary guidelines (NFG), which specify healthy food and lifestyle choices; highlight the need for an increased intake of fruit, vegetables, and whole-grains; and emphasize the importance of limiting the intake of processed and red meat; opting for low-salt foods; and avoiding all forms of alcohol throughout pregnancy (17). The recommended intake (RI) levels for a number of micronutrients are increased in pregnancy. Pregnant women are therefore advised to consume foods with high nutrient density, to ensure adequate intake levels of particularly folate, iron, calcium, vitamin D, and iodine. Evaluation of the diet in a population should thus include both the nutrient- and food-based dietary recommendations.

Assessing dietary intake in large cohort studies is essential for addressing potential diet-disease associations and informing the public about necessary health recommendations (18). Studies reporting on pregnant women's adherence to dietary guidelines in Nordic countries are few $(19,20)$. Therefore, the aim of the present study was to explore the intake of food and nutrients, from both diet and supplements, in a recently established cohort of pregnant women recruited from a general population, the Preventing Atopic dermatitis and Allergies in children (PreventADALL) study, and to evaluate their adherence to the NNR and the NFG. In addition, the study aimed to assess coffee and alcohol intake, as well as to evaluate the impact of educational level on dietary intake.

\section{Study design and methods}

\section{Cohort description}

Nutritional data in the present study is derived from the PreventADALL study, a multi-center, prospective, interventional, general population-based mother-child birth cohort study, aimed at the primary prevention of allergic 
disease. Study design, recruitment, and inclusion criteria are described in detail elsewhere (21).

\section{Participants and eligibility criteria}

Women were recruited from December 2014 to October 2016 by postal invitation from the three participating centers (Oslo University Hospital, Østfold Hospital Trust, and Karolinska Institutet, Stockholm) in connection with their first routine ultrasound examination around gestational week 18. During this period, pregnant women were invited to participate in the study with the following inclusion criteria: singleton and twin pregnancies between weeks 16 and 22 and sufficient Scandinavian language skills. Exclusion criteria were severe maternal or fetal disease. A total of 2,697 pregnant women were enrolled in Norway and Sweden, four of these contributing with two pregnancies.

Study enrollment, baseline interview, and height and weight measures were performed by trained personnel. Weight was recorded to the nearest $100 \mathrm{~g}$ by a digital scale, and height to the nearest $1 \mathrm{~mm}$ by a stadiometer. Maternal health, pre-pregnancy weight, and sociodemographic and lifestyle factors were obtained through electronic questionnaires, developed in collaboration with the University Center for Information Technology (USIT) at the University of Oslo. The participants received the first general electronic questionnaires within a week after inclusion with an automatic reminder in case of no response. The women were asked to specify the week of gestational age when completing the questionnaires. All women signed a written informed consent prior to study enrollment.

The PreventADALL study was approved by the Regional Committee for Medical and Health Research Ethics in South-Eastern Norway (2014/518) and in Sweden (2014/2242-31/4), and the study was registered at ClinicalTrials.gov (number NCT02449850).

\section{Dietary assessment}

The present dietary assessment was carried out in the Norwegian part of the PreventADALL cohort only, because the dietary assessment method was developed specifically for Norwegian food habits and meal patterns. The pregnant women were given access to the webbased, semi-quantitative food frequency questionnaire (PrevFFQ) via a link sent to their respective e-mails shortly after study inclusion. The PrevFFQ was designed to capture the habitual dietary intake during the first 4-5 months of pregnancy. The FFQ used in the PreventADALL study was previously validated in a population of women, using doubly labeled water and multiple 24-h-recalls (22). The PrevFFQ consisted of 279 questions on the frequency and amount of intake of about 280 food items, grouped according to the main food groups and meal patterns. Frequency categories were used in the increasing order: not at all, times per month, week or day. Amounts were given in portion sizes: standard units, spoons, cups, glasses, etc. The PrevFFQ included pictures of four different portion sizes for food items where portion size may be particularly difficult to estimate. The PrevFFQ included questions about the intake of vitamin or mineral supplements. Omission to answer a question would be followed by an automated comment, prompting the participant to submit an answer. All questions about diet in the FFQ were mandatory, assuring a complete set of values in all questionnaires. The data in the FFQ were transferred to the food and nutrient calculation system, Kostberegningssystemet (KBS), version 7.3, at the Department of Nutrition, University of Oslo, where all estimations of food and nutrient intakes were performed in KBS food composition database AE18. We included only women who answered the electronic questionnaires, excluding the first 125 enrolled women who received a paper version of the FFQ, thereby eliminating potential differences in results due to discrepancies in methods (paper vs. electronic FFQ). The possibility of double participation by four women who were enrolled with two pregnancies was eliminated, as the questionnaire from the first pregnancy was paper-based and therefore excluded. Women who reported unlikely energy intakes $(<4,000 \mathrm{~kJ} /$ day and $>20,000 \mathrm{~kJ} /$ day $)$ were also excluded, as well as three invalid FFQs and one study withdrawal, giving a total of 1,674 eligible study participants (23). A study overview and selection criteria are presented in Figure 1. A total of 154 out of the 1,674 women did not answer the 18-week general questionnaire. Therefore, some background information was only available for 1,520 women.

The NNR 2012 defined RI as 'the amount of a nutrient that meets the known requirement and maintains good nutritional status among practically all healthy individuals in a particular life stage or gender group' (16). Hence, we present the proportion of women that had intakes within the recommended intake range (RIR) or above the $\mathrm{RI}$, ensuring minimal probability for inadequacy. We did not assess the proportion of the group with relatively high probability of inadequate intake, defined as the proportion below average requirement (AR), as AR levels are not defined for pregnancy in the NNR. We included supplement intake when assessing the micronutrient intake through frequency estimations to increase the reliability of the results (24).

\section{Statistical analyses}

Data were exported from the KBS database and imported to SPSS (Statistical Package for the Social Sciences). All the analyses were performed using IBM $\odot$ SPSS $\odot$ statistics version 25 (Chicago, IL, USA). We conducted descriptive analyses of food intake, as well as energy intake, and macro- and micronutrient intake. Normal 


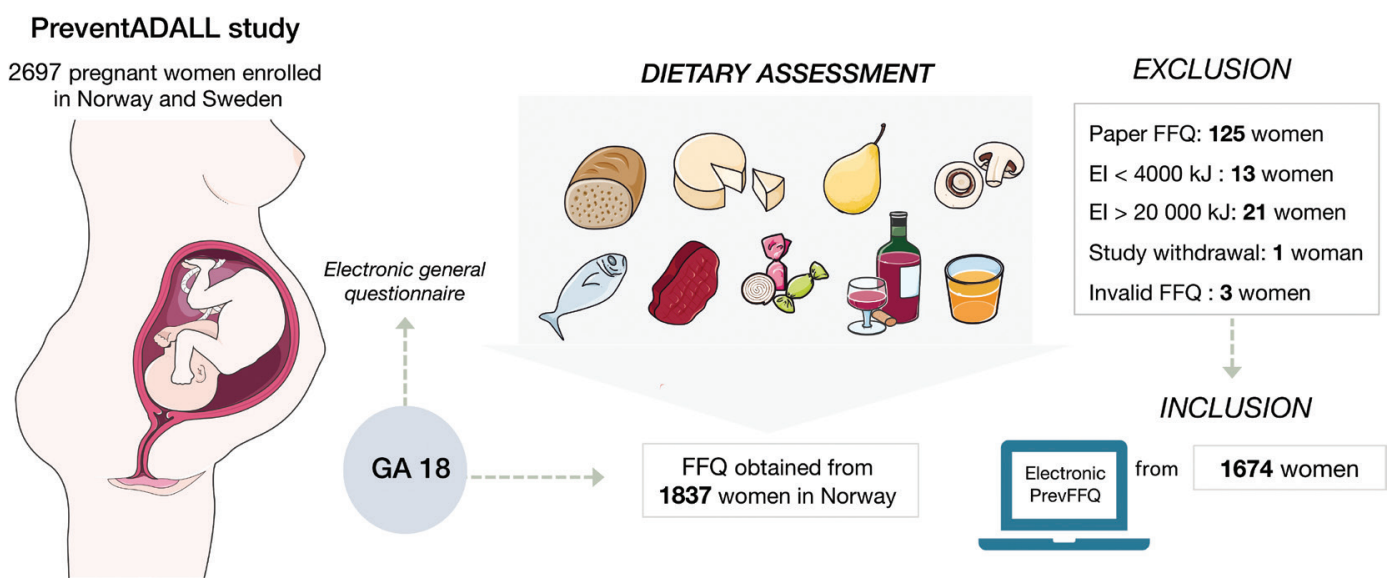

Fig. 1. Schematic overview of study and subjects, GA: gestational age, FFQ: Food Frequency Questionnaire. Participants with energy intakes $(\mathrm{EI})<4,000$ and $>20,000$ kilojoules $(\mathrm{kJ})$ were excluded.

distribution of variables was investigated through visual inspection of histograms and $p$-plots and by using the Kolmogorov-Smirnov test. Variables are described as means and standard deviations (SD) or median values with interquartile range (IQR) and 5th and 95th percentiles of proportions for normally and non-normally distributed variables, respectively. Descriptive statistics were used to investigate adherence to the recommendations on the frequency of consumption of micro- and macronutrients. Differences between categorical variables were analyzed by Chi-Square test and numerical data by One-Way ANOVA tests. One-way between groups ANOVA was performed to test whether educational level would influence the intake of micro- and macronutrients and food groups. The assumption of normality and homogeneity of variances was tested for each variable.

\section{Results}

Mean (SD) age of the population was 32.5 (4.1) years, and the mean (SD) pre-pregnancy body mass index (BMI) was $24.6(3.5) \mathrm{kg} / \mathrm{m}^{2}$. Other baseline characteristics are presented in Supplementary Table 1 for 1,520/1,674 respondents. Most $(90.8 \%)$ women had a Scandinavian background, $37.1 \%$ had one or more previous deliveries, $61.1 \%$ had a university-level education of more than 4 years, $81.0 \%$ reported a full-time job, $97.1 \%$ were married or cohabitating, and $52.7 \%$ had a yearly household income of $>1,000,000$ NOK.

Intakes and adherence to recommendations for macronutrients and the main food groups

The participants' intake of macronutrients and selected foods and beverages per day, as well as the proportion of participants with intakes in line with the recommendations, are presented in Table 1.
Median (IQR) energy intake was 10,082 $(4,139) \mathrm{kJ}$. Total fat intake was above RIR (25-40 E\%) in $14.0 \%$ of the women, and saturated fatty acid intake was above RI $(\max 10 \mathrm{E} \%)$ in $85.2 \%$ of the women. Average intake of fats is presented in Supplementary Table 2. Protein RIR (10-20 E\%) was met by $92.9 \%$, carbohydrate RIR (45-60 $\mathrm{E} \%$ ) by $55.6 \%$, and fiber RI (> $25 \mathrm{~g} /$ day) by $77.6 \%$ of the women.

The recommendations for vegetable intake ( $>250 \mathrm{~g} /$ day) was met by $75.6 \%$ and fresh fruit intake ( $>250 \mathrm{~g} /$ day) by $42.1 \%$ of women. A total of $52.2 \%$ exceeded the recommended intake for red meat ( $\max 500 \mathrm{~g} /$ week), and 60.3\% exceeded the recommended intake of fish and seafood (300-450 g/week). Daily salt intake was above recommendations ( $6 \mathrm{~g} /$ day) in $69.5 \%$ of women. The average intakes of other food groups and beverages are included in Supplementary Table 3.

Adherence to recommendations for micronutrients Table 2 shows the participant's estimated average daily intake of micronutrients compared to the RI levels (NNR 2012). Micronutrients deemed especially important during pregnancy and the intake of other micronutrients are listed in Supplementary Table 4. An intake below RI was seen in a high percentage of women for the following micronutrients: $54.4 \%$ for folate $(500 \mu \mathrm{g} /$ day $), 49.6 \%$ for iron ( $15 \mathrm{mg} /$ day), $36.2 \%$ for calcium ( $900 \mathrm{mg} /$ day), $24.4 \%$ for iodine $(175 \mu \mathrm{g} / \mathrm{day}), 41.3 \%$ for selenium (60 $\mu \mathrm{g} /$ day), and $28.7 \%$ for vitamin D (10 $\mu \mathrm{g} / \mathrm{day})$.

\section{Alcohol and coffee}

Almost a quarter (22.8\%) of the women reported an alcohol intake of $>1 \mathrm{~g} / \mathrm{day}, 4.4 \%$ an intake of $>10 \mathrm{~g} / \mathrm{day}$, and $1 \%$ an intake of $>15 \mathrm{~g} /$ day. Women reported their coffee consumption in cups. One cup was defined as $170 \mathrm{ml}$, equal 
Table 1. Estimated daily intake of macronutrients, salt, and selected foods, compared to dietary recommendations $(\mathrm{N}=1,674)$

\begin{tabular}{|c|c|c|c|c|c|c|c|c|c|}
\hline Macronutrient & Unit & Median & $\begin{array}{l}\text { Interquartile } \\
\text { range }\end{array}$ & $\begin{array}{c}\text { 5th } \\
\text { Percentile }\end{array}$ & $\begin{array}{c}\text { 95th } \\
\text { Percentile }\end{array}$ & $\begin{array}{c}\text { Recommended intake range } \\
\text { (RIR) (Nordic Nutrition } \\
\text { Recommendations } 2012 \\
\text { [NNR I2]) }\end{array}$ & $\begin{array}{c}\text { Below } \\
\text { RIR (\%) }\end{array}$ & $\begin{array}{c}\text { Above RIR } \\
(\%)\end{array}$ & $\begin{array}{c}\text { Within RIR } \\
(\%)\end{array}$ \\
\hline Carbohydrates & $\mathrm{E} \%$ & 45.7 & $42.3-49.2$ & 35.9 & 54.7 & $45-60 \mathrm{E} \%$ & 43.9 & 0.5 & 55.6 \\
\hline Protein & $\mathrm{E} \%$ & 16.5 & $|5|-.|8|$. & 13.1 & 20.5 & $10-20 \mathrm{E} \%$ & 0.2 & 6.9 & 92.9 \\
\hline Total fat & $\mathrm{E} \%$ & 34.5 & $31.2-37.8$ & 26.3 & 43.6 & $25-40 \mathrm{E} \%$ & 2.9 & 14.0 & 83.1 \\
\hline Saturated & $\mathrm{E} \%$ & 12.5 & $10.9-14.1$ & 8.7 & 17.0 & $\max 10 \mathrm{E} \%$ & 14.8 & 85.2 & 14.8 \\
\hline Monosaturated fat & $\mathrm{E} \%$ & 12.7 & | I.2-14.3 & 9.3 & 17.3 & $10-20 \mathrm{E} \%$ & 9.4 & 0.8 & 89.8 \\
\hline Polyunsaturated fat & $\mathrm{E} \%$ & 5.7 & $5.0-6.8$ & 4.0 & 9.2 & $5-10 \mathrm{E} \%$ & 23.7 & 3.3 & 73.0 \\
\hline Fiber & g/day & 32.2 & $25.0-41.3$ & 16.8 & 55.5 & $\min 25-35$ & 22.4 & 41.6 & 36.0 \\
\hline Food group & & & & & & $\begin{array}{l}\text { Recommended intake } \\
\text { range (RIR) (Norwegian } \\
\text { Food Based Dietary } \\
\text { Guidelines [NFG] 20II) }\end{array}$ & \multicolumn{3}{|c|}{ Adherence to NFG (\%) } \\
\hline Fruit and berries & g/day & 221 & $|4|-328$ & 61 & 623 & $\min 250 \mathrm{~g} /$ day & \multicolumn{3}{|c|}{42.1} \\
\hline Vegetables & g/day & 363 & $253-514$ & 141 & 802 & $\min 250 \mathrm{~g} /$ day & \multicolumn{3}{|c|}{75.6} \\
\hline Fish + seafood & g/week & 539 & $|88-79|$ & 121 & $\mathrm{I}, 274$ & $300-450 \mathrm{~g} /$ week $^{\mathrm{a}}$ & \multicolumn{3}{|c|}{$19.5(60.3 \%>R I R)$} \\
\hline Fatty fish & g/week & 136 & $7 I-206$ & 7 & 404 & $\min 200 \mathrm{~g} /$ week $^{\mathrm{b}}$ & \multicolumn{3}{|c|}{27.7} \\
\hline Red meat & g/week & 516 & $339-723$ & 116 & 1,100 & $\max 500 \mathrm{~g} /$ week $^{\mathrm{a}}$ & \multicolumn{3}{|c|}{47.8} \\
\hline Salt & g/day & 7.2 & $5.7-8.9$ & 3.9 & 12.2 & Max $6 \mathrm{~g} /$ day & \multicolumn{3}{|c|}{30.5} \\
\hline Coffee & g/day & 203 & $21-405$ & 0 & 878 & $170-340$ g/dayc & \multicolumn{3}{|c|}{59.1} \\
\hline Alcohol & g/day & 0.1 & $0.0-0.8$ & 0.0 & 9.3 & $0 \mathrm{~g} /$ day & \multicolumn{3}{|c|}{56.5} \\
\hline
\end{tabular}

NNRI 2 (Nordic Nutrition Recommendations 20I2), the NFG (Norwegian Food Based Dietary Guidelines) refer to only Norway; E\%: percentage of total energy intake per day;

${ }^{a}$ Recommendations given in gram per week.

bIncluded in the total amount of fish and seafood per week.

'Recommendations based on reference values established by the Department of Nutrition (25). Recommended daily intake is I-2 cups/day. One cup is equivalent to $170 \mathrm{~g}$ coffee. Caffeine content was calculated based on European Food Safety Authority (EFSA) guidelines (26): $44.5 \mathrm{mg}$ caffeine/l $00 \mathrm{~g}$ black coffee.

Table 2. Estimated daily intakes of selected micronutrients, compared to Nordic Nutrition Recommendations (NNR) $(N=1,674)$

\begin{tabular}{|c|c|c|c|c|c|c|c|c|}
\hline \multirow[t]{2}{*}{ Variable } & \multirow[t]{2}{*}{ Unit } & \multirow[t]{2}{*}{ Median } & \multirow{2}{*}{$\begin{array}{l}\text { Interquartile } \\
\text { range }\end{array}$} & \multirow{2}{*}{$\begin{array}{c}\text { 5th } \\
\text { Percentile }\end{array}$} & \multirow{2}{*}{$\begin{array}{c}\text { 95th } \\
\text { Percentile }\end{array}$} & \multirow{2}{*}{$\begin{array}{l}\text { Recommended } \\
\text { intake (NNR) }\end{array}$} & \multicolumn{2}{|c|}{ Percentage with intakes } \\
\hline & & & & & & & Below RI & Above RI \\
\hline Vitamin A & $\mathrm{RE}^{\mathrm{a}}$ & $\mathrm{I}, 694$ & 1,101 & 661 & 3,313 & $800 \mathrm{RE}^{\mathrm{a} / \mathrm{d} a y}$ & 9.6 & 90.4 \\
\hline Vitamin C & $\mathrm{mg}$ & 207 & 136 & 86 & 425 & $85 \mathrm{mg} /$ day & 4.4 & 95.6 \\
\hline Vitamin D & $\mu g$ & 13.6 & 12.1 & 4.2 & 32.6 & $10 \mu g /$ day & 28.7 & 71.3 \\
\hline Vitamin B 12 & $\mu g$ & 7.9 & 4.1 & 4.0 & 14.5 & $2 \mu g /$ day & 0.3 & 99.7 \\
\hline lodine & $\mu g$ & 256 & 189 & 103 & 563 & $175 \mu g /$ day & 24.4 & 75.6 \\
\hline Folate & $\mu g$ & 480 & 275 & 236 & 921 & $500 \mu \mathrm{g} /$ day & 54.4 & 45.6 \\
\hline Zinc & $\mathrm{mg}^{\mathrm{b}}$ & 15.5 & 14.8 & 7.7 & 43.4 & $9 \mathrm{mg} /$ day & 10.2 & 89.8 \\
\hline Calcium & $\mathrm{mg}$ & 1,045 & 558 & 495 & 1,960 & $900 \mathrm{mg} /$ day & 36.2 & 63.8 \\
\hline Selenium & $\mu g$ & 69 & 52 & 31 & 162 & $60 \mu g / d a y$ & 41.3 & 58.7 \\
\hline Iron & $\mathrm{mg}^{\mathrm{c}}$ & 15.1 & 10.0 & 7.3 & 92.0 & $>15^{\mathrm{d}} \mathrm{mg} / \mathrm{day}$ & 49.6 & 50.4 \\
\hline
\end{tabular}

RI: Recommended intake (NNR 2012) in pregnancy.

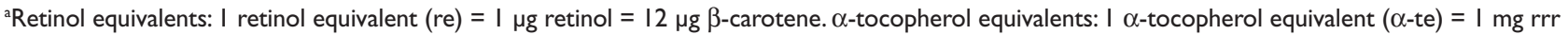
$\alpha$-tocopherol.

${ }^{\text {t}}$ The utilization of zinc is negatively influenced by phytic acid and positively influenced by animal protein. The recommended intakes are valid for a mixed animal/vegetable diet. For vegetarian cereal-based diets, a $25-30 \%$ higher intake is recommended.

cMeal composition influences the utilization of dietary iron. Availability increases if the diet contains abundant amounts of vitamin $\mathrm{C}$ and meat or fish daily, and it is decreased with simultaneous intake of polyphenols or phytic acid.

Increased need of iron intake during second and third trimesters in pregnancy. 
to $170 \mathrm{~g}$ of coffee. Median coffee intake was $203 \mathrm{~g} /$ day, and $40.9 \%$ of the women reported a daily coffee consumption above the recommended $340 \mathrm{~g}$ (27). Median caffeine intake from coffee was $90 \mathrm{mg} /$ day, and $19.4 \%$ exceeded a daily intake of $200 \mathrm{mg}$ of caffeine (RI max $200 \mathrm{~g} /$ day).

\section{Education level}

Post hoc comparisons using the Tukey's HSD test indicated that the median intake of red meat was significantly higher in participants with high school degree only and those with university education $\leq 4$ years, compared to women with university education $>4$ years $(P=0.015)$. We found a significantly higher intake of fiber $(P=0.002)$, vegetables $(P=0.001)$, and omega-3 $(P=0.001)$ in women with university education $>4$ years compared to women with high-school degree only. Coffee consumption increased with an increase in the educational level and was significantly higher in women with a university degree $>4$ years compared to high school only $(P=0.005)$. Alcohol intake differed significantly between different educational groups $(P=0.004$, Kruskal-Wallis test). Women with a university education $>4$ years had a significantly higher alcohol intake ( $P=0.016$, adjusted with Bonferroni) compared to those with lower educational level. We found no associations between educational levels and micronutrient intakes. Income levels did not significantly associate with dietary or alcohol and coffee intake.

\section{Discussion}

Our assessment of dietary intake during pregnancy in a mother-child cohort from the general Norwegian population showed that a large number of participants had satisfactory intakes of healthy food items, such as fiber, vegetables, and fish. However, a significant part of our population was at risk for macro- and micronutrient inadequacy, with particularly low adherence levels for folate, iron, selenium, calcium, vitamin $\mathrm{D}$, and iodine. Self-reported red meat, salt, and saturated fatty acid intake exceeded recommendations in more than half of the subjects in the cohort, and together with alcohol and coffee consumption, they were associated with higher educational level.

\section{Macronutrient- and food intakes}

The satisfactory intake of healthy food items by most women in our study is in line with a previous study showing that Nordic diets are commonly characterized by a high consumption of milk and dairy products, moderate to high consumption of meat, and moderate consumption of fruit and vegetables (16). Appropriate birthweight (weight between the 10th and the 90th percentiles) may be facilitated by a maternal plant-food-based dietary pattern, with high intakes of fruit and vegetables, low-fat dairy, and lean meats throughout pregnancy $(28,29)$. The high vegetable and fiber intake in our cohort, in line with a previous study showing that Norwegian women tend to increase their fruit and vegetable consumption from pre-pregnancy to early pregnancy (30), will likely have positive health effects for both mother and child. A higher intake of fruits and vegetables is also associated with increased infant growth up to 6 months of age (31). Our study was not designed to assess pre-pregnancy dietary habits, but a heightened motivation in pregnancy might have played a role in increasing vegetable consumption in our study population, resulting in the reported high intakes of vegetables. Although estimated vegetable and fiber intake was satisfactory at the group level, more than half of the women in our study population did not meet the recommended daily intake of fruit $(250 \mathrm{~g} / \mathrm{d})$. Total fish and seafood intake in our cohort was higher than in a study with 119 pregnant Norwegian women reporting a total fish intake of $39 \mathrm{~g} /$ day, which is only half of the intake found in our study (32). The high intake of fish and seafood is likely to be beneficial also for the offspring, as maternal fish intake in pregnancy has been associated with positive fetal neurodevelopmental outcomes and reduced levels of allergic disease $(33,34)$. In spite of its nutritional benefits, fish is also a known source of mercury and other environmental toxins, which can have a negative impact on fetal development (35). Therefore, the benefits of fish intake above the recommended intake levels, as seen in many women in our study, need to be weighed against the potential detrimental effects. The high intake of red meat, salt, and saturated fat in our study is consistent with data from a large meta-analysis concluding that the overall fat and saturated fat intake is above the recommended levels in most pregnant women in high-income countries, whereas carbohydrate intake is below the recommended levels(12). The majority of women in our study had salt intakes above RI levels, which is in line with a Canadian study comprising 1,533 pregnant women reporting sodium intakes above the recommended levels in $85 \%$ of the participants (36). Excessive consumption of saturated fat and low intakes of omega 3 fatty acids have been linked to adverse health outcomes in both mother and child $(37,38)$. Knudsen et al. showed in a large cohort of pregnant Danish women that high intakes of red- and processed meat and high fat dairy was associated with an increased risk of having a child small for gestational age (9).

\section{Micronutrient intake}

Our findings of low adherence to RI for some micronutrients is in line with the consistently reported rise of lower-quality diets in many industrialized countries, leading to an inadequate intake of particularly iron, folic acid, calcium, and vitamin D among pregnant women $(39,40)$. The potentially inadequate intake of vitamin $\mathrm{D}$, folate, and iron is supported by similar findings in 118 pregnant 
Finnish women (41). Significant folate deficiencies were observed in about half of the population of 204 Italian pregnant women and women of childbearing age (42). A low reported folate intake, such as observed in our study, is in line with inadequate periconceptional use of folic acid supplement in Oslo (43) and could potentially have serious consequences for the developing fetus (44). Inadequate folate intakes in pregnancy have also been described in Sweden and other European countries $(12,45)$. Pregnant Norwegian women are advised to use supplementation with $400 \mathrm{mg}$ of folic acid/day, starting 1 month before conception until 2-3 months of pregnancy (46), as food is not fortified with folic acid. More than half of our study population reported a daily fruit consumption below the RI. It is likely that an inadequate intake of fruit contributes to low folate intakes in many of the pregnant women. Although the prevalence of iodine deficiency among pregnant women in Europe has been well-known for decades, intake still seems to be insufficient in many countries, including Norway (47). A quarter of the women in our study reported iodine intakes below the RI, in line with a representative Norwegian population (Norkost 3), showing unsatisfactory iodine intakes in $46 \%$ of women from the general population (48). Other studies have revealed mild-to-moderate iodine deficiencies in a large number of pregnant Norwegian women (49), likely because diet alone seems to be insufficient in maintaining adequate iodine concentrations (50). Iodine deficiency can cause severe adverse effects in the child, such as impaired cognitive outcomes and delayed neurodevelopment $(51,52)$. Reported vitamin D intake was higher in our study (13.6 $\mu \mathrm{g} /$ day) compared to a large Norwegian cohort study of more than 40,108 pregnant women conducted approximately 15 years ago, in which $63 \%$ did not reach the RI level of $10 \mu \mathrm{g} /$ day, in spite of high vitamin D supplementation rates (19). Public health efforts in the past decade might have increased the awareness of Vitamin D and its importance, and contributed to higher intake rates in our study. Although previous studies have generally reported sufficient maternal calcium intakes in the United States, the United Kingdom, and Europe, we found a significant number of women at risk for potentially inadequate intakes (12). Low selenium intakes have also previously been reported in Western countries, particularly in inhabitants of Northern Europe (53). In a study of 230 pregnant women in the United Kingdom, the majority had an overall low selenium status (54). Low maternal selenium levels in pregnancy may adversely affect the child's psychomotor development $(55,56)$. Adequate maternal zinc intake is also crucial for normal fetal development (57). Most women in our study reported zinc intakes above the RI, which is in agreement with previous reports from other European countries (12).

\section{Coffee and alcohol}

Daily caffeine intake was higher in our study than in the MoBa study, which assessed caffeine intake in 59,123 pregnant women in Norway and found that $10 \%$ of the women exceeded the caffeine level of $200 \mathrm{mg} /$ day (41). The high rate of women exceeding recommendations for coffee intake in our study (41\%) is a matter of concern. Maternal caffeine intake in pregnancy has been associated with reduced birthweight in relation to gestational weight in the Norwegian MoBa study, a large prospective observational cohort study (58), in line with other studies (59-61). Although women in our study tended to give up lifestyle choices that could harm their unborn child, such as the consumption of nicotine-containing products (62), we found a high number of women reporting alcohol intake in the first 4-5 months of pregnancy. The adverse effects of alcohol on the fetus are well known and an important reason for many women to abstain from alcohol during pregnancy (63). Severe effects on the fetus are seen with an alcohol intake above 24-48 g/day; however, even lower levels of alcohol consumption can adversely affect the developing fetus. Due to uncertainty of the threshold level for negative health effects in the offspring, it is recommended to totally abstain from alcohol in pregnancy (64). A large meta-analysis concluded that approximately $10 \%$ of women globally report alcohol intake in pregnancy. The highest prevalence was seen in European countries, where up to a quarter of women consumed alcohol in pregnancy (15). The large Norwegian MoBa study reported alcohol consumption among $31.8 \%$ of women in the first trimester and among $9.7 \%$ in the second trimester. The majority of these women consumed alcoholic beverages less than once a month (65). Contrary to these findings, a recent study comprising 575 Norwegian women found that $27 \%$ reported weekly alcohol intake before pregnancy, compared with none in early pregnancy (66). We found a higher alcohol consumption in women with higher educational level, which is comparable to the findings of the MoBa study (65). Similarly, a Danish study in 100,000 pregnant women found that binge drinking in the pre-recognized part of pregnancy was more common among well-educated women (67). It has been suggested that alcohol consumption in pregnancy might increase around the globe in the coming years, which could cause a surge of alcohol-related birth defects (68). Our findings therefore warrant special attention.

Apart from a higher intake of alcohol and coffee, our results suggest that women with a higher educational level eat more healthy foods, such as whole-grain foods, vegetables, foods rich in omega 3 , and have a reduced intake of red meat. The tendency toward better dietary quality in these women was not surprising, as higher education independently influences better food choice (69). A large body of evidence points to the influence of social class 
on diet and lifestyle $(70,71)$. Similar to our findings, a Spanish study assessing dietary intake and compliance to national food guidelines found that less educated women reported lower intakes of omega-3 fatty acids, and higher intakes of saturated fatty acids (72). Greater financial and social resources possibly provide for better means to support a healthy lifestyle, although we found no association between income and dietary intake in our study (70).

\section{Strengths and limitations}

A major strength of the present study is the robust sample size from a general population, which ensures a large variation of dietary habits. All FFQs are subject to large between-person errors. In addition, self-reported data are prone to systematic bias and methodological challenges (73), such as social desirability bias. This bias regularly occurs because study participants tend to answer questions in a way that will be viewed favorably by others, which leads to overreporting of good dietary habits and underreporting of unhealthy habits. Consequently, overreporting intakes of fiber and healthy food items, such as vegetables and fruit, is a common issue with FFQs. In spite of its limitations, the FFQ remains the most-used instrument, especially in large cohorts.

Women in the PreventADALL study are older, wealthier, better educated, and less often smokers and single, compared with the general pregnant population in Norway, which might limit the generalizability of our results $(74,75)$. Moreover, our dietary intake data may not be representable for pregnant women in other countries or other ethnicities, and therefore the implications may differ in other settings.

\section{Conclusion}

Dietary intake in a large cohort of Norwegian pregnant women in a mother-child birth cohort showed low adherence to recommendations with regard to saturated fat, total carbohydrates, folate, iron, calcium, vitamin D, and iodine. Women with a university degree showed a tendency towards healthier eating habits, except for higher intakes of alcohol and coffee. Thus, our results highlight the role of education in dietary decision-making.

A sufficient nutrient supply in pregnancy is crucial for ensuring favorable maternal and fetal health outcomes. Intervention strategies, aimed at educating pregnant women and encouraging healthful dietary choices, may therefore be needed for women at all educational levels.

\section{Acknowledgments}

The authors express immense gratitude to the study participants and all individuals involved in facilitating and running the study. The study was performed within the ORAACLE Group (the Oslo Research Group of Asthma and Allergy in Childhood; the Lung and Environment)

\section{Conflict of interest and funding}

Eva Maria Rehbinder has received honoraria for presentations from Sanofi Genzyme, Novartis, MEDA, and Omega Pharma; Karin C. Lødrup Carlsen has received honorarium for presentation from Thermo Fisher Scientific. All other authors have no conflicts of interest to disclose. The study was approved by the local ethics committee and was conducted in accordance with the Declaration of Helsinki 1975, as revised in 2008. The PreventADALL study has been funded by the following public funding bodies: the Regional Health Board South East, the Norwegian Research Council, Oslo University Hospital, the University of Oslo, Health and Rehabilitation Norway, the Foundation for Healthcare and Allergy Research in Sweden - Vårdalstiftelsen, Swedish Asthma and Allergy Association's Research Foundation, Swedish Research Council - the Initiative for Clinical Therapy Research, the Swedish Heart-Lung Foundation, SFO-V Karolinska Institutet, Østfold Hospital Trust, the European Union (MeDALL project), the Norwegian Association of Asthma and Allergy, the Kloster Foundation, Fürst Medical Laboratory, the Norwegian Society of Dermatology and Venereology, and Arne Ingel's bequest.

\section{Clinical trial registration}

The ClinicalTrials.gov registration number for this study is NCT02449850.

\section{References}

1. O'Connor DL, Blake J, Bell R, Bowen A, Callum J, Fenton $\mathrm{S}$, et al. Canadian consensus on female nutrition: adolescence, reproduction, menopause, and beyond. J Obstet Gynaecol Can. 2016;38(6):508-54.e18. doi: 10.1016/j.jogc.2016.01.001

2. Koletzko B, Bauer C-P, Bung P, Cremer M, Flothkötter M, Hellmers C, et al. [Nutrition in pregnancy - Practice recommendations of the Network 'Healthy Start - Young Family Network']. Dtsch Med Wochenschr 1946. 2012;137(25-26):1366-72. doi: $10.1055 / \mathrm{s}-0032-1305076$

3. Black RE, Allen LH, Bhutta ZA, Caulfield LE, Onis M de, Ezzati $\mathrm{M}$, et al. Maternal and child undernutrition: global and regional exposures and health consequences. The Lancet. 2008;371(9608):243-60. doi: 10.1016/S0140-6736(07)61690-0

4. Kind KL, Moore VM, Davies MJ. Diet around conception and during pregnancy - effects on fetal and neonatal outcomes. Reprod Biomed Online. 2006;12(5):532-41. doi: 10.1016/ s1472-6483(10)61178-9

5. Godfrey KM, Barker DJ. Fetal programming and adult health. Public Health Nutr. 2001;4(2B):611-24. doi: 10.1093/ ajcn/71.5.1344s

6. Langley-Evans SC. Nutrition in early life and the programming of adult disease: a review. J Hum Nutr Diet Off J Br Diet Assoc. 2015;28 Suppl 1:1-14. doi: 10.1111/jhn.12212

7. Cordain L, Eaton SB, Sebastian A, Mann N, Lindeberg S, Watkins BA, et al. Origins and evolution of the Western diet: health implications for the 21st century. Am J Clin Nutr. 2005;81(2):341-54. doi: 10.1093/ajcn.81.2.341

8. Timmermans S, Steegers-Theunissen RP, Vujkovic M, den Breeijen H, Russcher H, Lindemans J, et al. The Mediterranean 
diet and fetal size parameters: The Generation R Study. Br J Nutr. 2012;108(8):1399-409. doi: 10.1017/S000711451100691X

9. Knudsen VK, Orozova-Bekkevold IM, Mikkelsen TB, Wolff S, Olsen SF. Major dietary patterns in pregnancy and fetal growth. Eur J Clin Nutr. 2008;62(4):463-70. doi: 10.1038/sj.ejen.1602745

10. Christian P, Stewart CP. Maternal micronutrient deficiency, fetal development, and the risk of chronic disease. J Nutr. 2010;140(3):437-45. doi: 10.3945/jn.109.116327

11. Popkin BM. Global nutrition dynamics: the world is shifting rapidly toward a diet linked with noncommunicable diseases. Am J Clin Nutr. 2006 Aug;84(2):289-98. doi: 10.1093/ajcn/84.1.289

12. Blumfield ML, Hure AJ, Macdonald-Wicks L, Smith R, Collins CE. Systematic review and meta-analysis of energy and macronutrient intakes during pregnancy in developed countries. Nutr Rev. 2012;70(6):322-36. doi: 10.1111/j.1753-4887.2012.00481.x

13. Gernand AD, Schulze KJ, Stewart CP, West KP, Christian P. Micronutrient deficiencies in pregnancy worldwide: health effects and prevention. Nat Rev Endocrinol. 2016;12(5):274-89. doi: 10.1038/nrendo.2016.37

14. Trumpff C, De Schepper J, Tafforeau J, Van Oyen H, Vanderfaeillie J, Vandevijvere S. Mild iodine deficiency in pregnancy in Europe and its consequences for cognitive and psychomotor development of children: a review. J Trace Elem Med Biol Organ Soc Miner Trace Elem GMS. 2013;27(3):174-83. doi: 10.1016/j.jtemb.2013.01.002

15. Popova S, Lange S, Probst C, Gmel G, Rehm J. Estimation of national, regional, and global prevalence of alcohol use during pregnancy and fetal alcohol syndrome: a systematic review and meta-analysis. Lancet Glob Health. 2017;5(3):e290-9. doi: 10.1016/S2214-109X(17)30021-9

16. Nordic Nutrition Recommendations 2012 [Internet]. Nordic cooperation. Available from: https://www.norden.org/en/publication/nordic-nutrition-recommendations-2012-0 [cited 16 October 2018].

17. Kostråd for å fremme folkehelsen og forebygge kroniske sykdommer - Metodologi og vitenskapelig kunnskapsgrunnlag [Internet]. Helsedirektoratet.no. Available from: https://helsedirektoratet.no/ publikasjoner/kostrad-for-a-fremme-folkehelsen-og-forebyggekroniske-sykdommer-metodologi-og-vitenskapelig-kunnskaps grunnlag [cited 08 November 2018].

18. Subar AF, Freedman LS, Tooze JA, Kirkpatrick SI, Boushey C, Neuhouser ML, et al. Addressing current criticism regarding the value of self-report dietary data. J Nutr. 2015;145(12):2639-45. doi: $10.3945 /$ jn.115.219634

19. Haugen M, Brantsaeter AL, Alexander J, Meltzer HM. Dietary supplements contribute substantially to the total nutrient intake in pregnant Norwegian women. Ann Nutr Metab. 2008;52(4):272-80. doi: 10.1159/000146274

20. von Ruesten A, Brantsæter AL, Haugen M, Meltzer HM, Mehlig $\mathrm{K}$, Winkvist A, et al. Adherence of pregnant women to Nordic dietary guidelines in relation to postpartum weight retention: results from the Norwegian Mother and Child Cohort Study. BMC Public Health. 2014;14:75. doi: 10.1186/1471-2458-14-75

21. Lødrup Carlsen KC, Rehbinder EM, Skjerven HO, Carlsen MH, Fatnes TA, Fugelli P, et al. Preventing Atopic Dermatitis and ALLergies in children-the prevent ADALL study. Allergy. 2018;73:2063-70. doi: 10.1111/all.13468

22. Medin AC, Carlsen MH, Hambly C, Speakman JR, Strohmaier S, Andersen LF. The validity of a web-based FFQ assessed by doubly labelled water and multiple 24-h recalls. Br J Nutr. 2017;118(12):1106-17. doi: 10.1017/S0007114517003178

23. Meltzer HM, Brantsaeter AL, Ydersbond TA, Alexander J, Haugen M. Methodological challenges when monitoring the diet of pregnant women in a large study: experiences from the Norwegian Mother and Child Cohort Study (MoBa). Matern Child Nutr. 2008;4(1):14-27. doi: 10.1111/j.1740-8709.2007.00104.x

24. Ortiz-Andrellucchi A, Doreste-Alonso J, Henríquez-Sánchez P, Cetin I, Serra-Majem L. Dietary assessment methods for micronutrient intake in pregnant women: a systematic review. Br J Nutr. 2009;102 Suppl 1:S64-86. doi: 10.1017/S0007114509993151

25. mål vekt og porsjonsstørrelser for matvarer [Internet]. Available from: https://www.google.com $/$ search?q $=\mathrm{m} \% \mathrm{C} 3 \% \mathrm{~A} 51+\mathrm{vekt}+$ og + porsjonsst $\%$ C $3 \%$ B 8 rrelser + for + matvarer\&oq $=$ $\mathrm{m} \% \mathrm{C} 3 \% \mathrm{~A} 51+$ vekt + og\&aqs $=$ chrome. $0.0 \mathrm{j} 69 \mathrm{i} 57 \mathrm{j} 014.2557 \mathrm{j} 0 \mathrm{j} 7$ \&sourceid=chrome\&ie=UTF-8 [cited 12 June 2019].

26. EFSA NDA Panel (EFSA Panel on Dietetic Products, Nutrition and Allergies), 2015. Scientific Opinion on the safety of caffeine. EFSA Journal 2015;13(5):4102. doi: 10.2903/j.efsa.2015.4102

27. Gode levevaner før og i svangerskapet - Helsedirektoratet [Internet]. Available from: https://www.helsedirektoratet.no/ brosjyrer/gode-levevaner-for-og-i-svangerskapet [cited 22 July 2019].

28. Grieger JA, Clifton VL. A review of the impact of dietary intakes in human pregnancy on infant birthweight. Nutrients. 2014;7(1):153-78. doi: 10.3390/nu7010153

29. Englund-Ögge L, Brantsæter AL, Sengpiel V, Haugen M, Birgisdottir BE, Myhre R, et al. Maternal dietary patterns and preterm delivery: results from large prospective cohort study. BMJ. 2014;348:g1446. doi: 10.1136/bmj.g1446

30. Skreden M, Bere E, Sagedal LR, Vistad I, Øverby NC. Changes in fruit and vegetable consumption habits from pre-pregnancy to early pregnancy among Norwegian women. BMC Pregnancy Childbirth. 2017;17(1):107. doi: 10.1186/s12884-017-1291-y

31. Jang W, Kim H, Lee B-E, Chang N. Maternal fruit and vegetable or vitamin $\mathrm{C}$ consumption during pregnancy is associated with fetal growth and infant growth up to 6 months: results from the Korean Mothers and Children's Environmental Health (MOCEH) cohort study. Nutr J. 2018;17(1):105. doi: 10.1186/ s12937-018-0410-6

32. Brantsaeter AL, Haugen M, Thomassen Y, Ellingsen DG, Ydersbond TA, Hagve T-A, et al. Exploration of biomarkers for total fish intake in pregnant Norwegian women. Public Health Nutr. 2010;13(1):54-62. doi: 10.1017/S1368980009005904

33. Venter C, Brown KR, Maslin K, Palmer DJ. Maternal dietary intake in pregnancy and lactation and allergic disease outcomes in offspring. Pediatr Allergy Immunol Off Publ Eur Soc Pediatr Allergy Immunol. 2017;28(2):135-43. doi: 10.1111/pai.12682

34. Starling P, Charlton K, McMahon AT, Lucas C. Fish intake during pregnancy and foetal neurodevelopment - a systematic review of the evidence. Nutrients. 2015;7(3):2001-14. doi: 10.3390/nu7032001. doi: 10.1515/jpm-2013-0349

35. Solan TD, Lindow SW. Mercury exposure in pregnancy: a review. J Perinat Med. 2014;42(6):725-9. doi: 10.1515/jpm-2

36. Dubois L, Diasparra M, Bédard B, Colapinto CK, FontaineBisson B, Morisset A-S, et al. Adequacy of nutritional intake from food and supplements in a cohort of pregnant women in Québec, Canada: the 3D Cohort Study (Design, Develop, Discover). Am J Clin Nutr. 2017;106(2):541-8. doi: 10.3945/ajen.117.155499

37. Chia A-R, Chen L-W, Lai JS, Wong CH, Neelakantan N, van Dam RM, et al. Maternal dietary patterns and birth outcomes: a systematic review and meta-analysis. Adv Nutr Bethesda Md. 2019;10:685-95. doi: 10.1093/advances/nmy123

38. Bowers K, Tobias DK, Yeung E, Hu FB, Zhang C. A prospective study of prepregnancy dietary fat intake and risk of gestational diabetes. Am J Clin Nutr. 2012;95(2):446-53. doi: 10.3945/ ajcn.111.026294 
39. Parisi F, Laoreti A, Cetin I. Multiple micronutrient needs in pregnancy in industrialized countries. Ann Nutr Metab. 2014;65(1):13-21. doi: 10.1159/000365794

40. Giddens JB, Krug SK, Tsang RC, Guo S, Miodovnik M, Prada JA. Pregnant adolescent and adult women have similarly low intakes of selected nutrients. J Am Diet Assoc. 2000;100(11):1334 40. doi: 10.1016/S0002-8223(00)00377-1

41. Erkkola M, Karppinen M, Järvinen A, Knip M, Virtanen SM. Folate, vitamin $\mathrm{D}$, and iron intakes are low among pregnant Finnish women. Eur J Clin Nutr. 1998 Oct;52(10):742-8.

42. Agodi A, Barchitta M, Valenti G, Quattrocchi A, Marchese AE, Oliveri Conti G, et al. Dietary folate intake and blood biomarkers reveal high-risk groups in a Mediterranean population of healthy women of childbearing potential. Ann Nutr Metab. 2013;63(3):179-85. doi: 10.1159/000346962

43. Braekke K, Staff AC. Periconceptional use of folic acid supplements in Oslo. Acta Obstet Gynecol Scand. 2003;82(7):620-7.

44. Wald NJ, Law MR, Morris JK, Wald DS. Quantifying the effect of folic acid. Lancet Lond Engl. 2001;358(9298):2069-73.

45. Lundqvist A, Johansson I, Wennberg A, Hultdin J, Högberg $\mathrm{U}$, Hamberg K, et al. Reported dietary intake in early pregnant compared to non-pregnant women - a cross-sectional study. BMC Pregnancy Childbirth. 2014;14:373. doi: 10.1186/ s12884-014-0373-3

46. Folat og graviditet - NHI.no [Internet]. Available from: https:// nhi.no/familie/graviditet/svangerskap-og-fodsel/livsstil/svangerskap-gode-rad/folat-og-graviditet/ [cited 22 May 2019].

47. Zimmermann M, Delange F. Iodine supplementation of pregnant women in Europe: a review and recommendations. Eur J Clin Nutr. 2004;58(7):979-84. doi: 10.1038/sj.ejcn.1601933

48. Carlsen MH, Andersen LF, Dahl L, Norberg N, Hjartåker A. New iodine food composition database and updated calculations of iodine intake among Norwegians. Nutrients. 2018;10(7):930. doi: 10.3390/nu10070930

49. Henjum S, Aakre I, Lilleengen AM, Garnweidner-Holme L, Borthne S, Pajalic Z, et al. Suboptimal Iodine status among pregnant women in the Oslo Area, Norway. Nutrients. 2018;10(3):280. doi: 10.3390/nu10030280

50. Dahl L, Wik Markhus M, Sanchez PVR, Moe V, Smith L, Meltzer HM, et al. Iodine deficiency in a study population of Norwegian pregnant women-results from the Little in Norway Study (LiN). Nutrients. 2018;10(4):513. doi: 10.3390/ nu10040513

51. Bath SC, Steer CD, Golding J, Emmett P, Rayman MP. Effect of inadequate iodine status in UK pregnant women on cognitive outcomes in their children: results from the Avon Longitudinal Study of Parents and Children (ALSPAC). Lancet Lond Engl. 2013;382(9889):331-7. doi: 10.1016/S0140-6736(13)60436-5

52. Abel MH, Caspersen IH, Meltzer HM, Haugen M, Brandlistuen $\mathrm{RE}$, Aase H, et al. Suboptimal maternal iodine intake is associated with impaired child neurodevelopment at 3 years of age in the Norwegian mother and child cohort study. J Nutr. 2017;147(7):1314-24. doi: 10.3945/jn.117.250456

53. Rayman MP. The importance of selenium to human health. Lancet Lond Engl. 2000;356(9225):233-41. doi: 10.1016/S01406736(00)02490-9

54. Rayman MP, Bath SC, Westaway J, Williams P, Mao J, Vanderlelie JJ, et al. Selenium status in U.K. pregnant women and its relationship with hypertensive conditions of pregnancy. Br J Nutr. 2015;113(2):249-58. doi: 10.1017/S000711451400364X

55. Skröder HM, Hamadani JD, Tofail F, Persson LÅ, Vahter ME, Kippler MJ. Selenium status in pregnancy influences children's cognitive function at 1.5 years of age. Clin Nutr Edinb Scotl. 2015;34(5):923-30. doi: 10.1016/j.clnu.2014.09.020

56. Polanska K, Krol A, Sobala W, Gromadzinska J, Brodzka R, Calamandrei G, et al. Selenium status during pregnancy and child psychomotor development-Polish mother and child cohort study. Pediatr Res. 2016;79(6):863-9. doi: 10.1038/pr.2016.32

57. King JC. Determinants of maternal zinc status during pregnancy. Am J Clin Nutr. 2000;71(5 Suppl):1334S-43S. doi: 10.1093/ ajen/71.5.1334s

58. Sengpiel V, Elind E, Bacelis J, Nilsson S, Grove J, Myhre R, et al. Maternal caffeine intake during pregnancy is associated with birth weight but not with gestational length: results from a large prospective observational cohort study. BMC Med. 2013;11(1):42. doi: 10.1186/1741-7015-11-42

59. Grosso LM, Triche EW, Belanger K, Benowitz NL, Holford TR, Bracken MB. Caffeine metabolites in umbilical cord blood, cytochrome P-450 1A2 activity, and intrauterine growth restriction. Am J Epidemiol. 2006;163(11):1035-41. doi: 10.1093/aje/ kwj125

60. Ørskou J, Henriksen TB, Kesmodel U, Secher NJ. Maternal characteristics and lifestyle factors and the risk of delivering high birth weight infants. Obstet Gynecol. 2003;102(1): 115-20.

61. Group BMJP. Maternal caffeine intake during pregnancy and risk of fetal growth restriction: a large prospective observational study. BMJ. 2010;340:c2331. doi: 10.1136/bmj.c2331

62. KreybergI, Bains KES, Carlsen K-H, GranumB, Gudmundsdóttir HK, Haugen G, et al. Stopping when knowing: use of snus and nicotine during pregnancy in Scandinavia. ERJ Open Res. 2019;5(2):00197-2018. doi: 10.1183/23120541.00197-2018

63. Forbes LE, Graham JE, Berglund C, Bell RC. Dietary change during pregnancy and women's reasons for change. Nutrients. 2018;10(8):1032. doi: 10.3390/nu10081032

64. Ornoy A, Ergaz Z. Alcohol abuse in pregnant women: effects on the fetus and newborn, mode of action and maternal treatment. Int J Environ Res Public Health. 2010;7(2):364-79. doi: 10.3390/ ijerph7020364

65. Magnus MC, DeRoo LA, Håberg SE, Magnus P, Nafstad $\mathrm{P}$, Nystad W, et al. Prospective study of maternal alcohol intake during pregnancy or lactation and risk of childhood asthma: the Norwegian mother and child cohort study. Alcohol Clin Exp Res. 2014;38(4):1002-11. doi: 10.1111/acer.12348

66. Skreden M, Bere E, Sagedal LR, Vistad I, Øverby NC. Changes in beverage consumption from pre-pregnancy to early pregnancy in the Norwegian Fit for Delivery study. Public Health Nutr. 2015;18(7):1187-96. doi: 10.1017/S136898001400189X

67. Strandberg-Larsen K, Rod Nielsen N, Nybo Andersen A-M, Olsen J, Grønbaek M. Characteristics of women who binge drink before and after they become aware of their pregnancy. Eur J Epidemiol. 2008;23(8):565-72. doi: 10.1007/ s10654-008-9265-Z

68. Lim SS, Vos T, Flaxman AD, Danaei G, Shibuya K, Adair-Rohani H, et al. A comparative risk assessment of burden of disease and injury attributable to 67 risk factors and risk factor clusters in 21 regions, 1990-2010: a systematic analysis for the Global Burden of Disease Study 2010. Lancet Lond Engl. 2012;380(9859):2224-60. doi: 10.1016/S0140-6736(12) 61766-8

69. Kearney M, Kearney J, Dunne A, Gibney M. Sociodemographic determinants of perceived influences on food choice in a nationally representative sample of Irish adults. Public Health Nutr. 2000;3(2):219-26. 
70. Darmon N, Drewnowski A. Does social class predict diet quality? Am J Clin Nutr. 2008;(5):1107-17. doi: 10.1093/ajen/87. 5.1107

71. Emmett PM, Jones LR, Golding J. Pregnancy diet and associated outcomes in the Avon longitudinal study of parents and children. Nutr Rev. 2015;73 Suppl 3:154-74. doi: 10.1093/ nutrit/nuv053

72. Rodríguez-Bernal CL, Ramón R, Quiles J, Murcia M, Navarrete-Muñoz EM, Vioque J, et al. Dietary intake in pregnant women in a Spanish Mediterranean area: as good as it is supposed to be? Public Health Nutr. 2013;16(8):1379-89. doi: $10.1017 / \mathrm{S} 1368980012003643$

73. Freedman LS, Schatzkin A, Midthune D, Kipnis V. Dealing with dietary measurement error in nutritional cohort studies. J Natl Cancer Inst. 2011;103(14):1086-92. doi: 10.1093/jnci/djr189
74. Nilsen RM, Vollset SE, Gjessing HK, Skjaerven R, Melve KK, Schreuder P, et al. Self-selection and bias in a large prospective pregnancy cohort in Norway. Paediatr Perinat Epidemiol. 2009;23(6):597-608. doi: 10.1111/j.1365-3016.2009.01062.x

75. Home [Internet]. ssb.no. Available from: https://www.ssb.no/en [cited 04 November 2019].

\section{* Carina Madelen Saunders}

Division of Paediatric and Adolescent Medicine

Oslo University Hospital

Postboks 4950, Nydalen

NO-0424 Oslo

Norway

E-mail: carinamadelensaunders@gmail.com 